\title{
A Pooled Analysis of the Efficacy and Safety of Saxagliptin as Monotherapy in Patients with Type 2 Diabetes
}

\section{Boaz Hirshberg ${ }^{1 *}$, Brian Bryzinski' ${ }^{1}$ John $\mathrm{Xu}^{1}$ and Nayyar Iqbal ${ }^{2}$}

${ }^{1}$ AstraZeneca, Gaithersburg, MD, USA

${ }^{2}$ Bristol-Myers Squibb, Princeton, NJ, USA

\begin{abstract}
Objective: Saxagliptin is a once-daily, orally administered dipeptidyl peptidase-4 inhibitor, approved for the treatment of type 2 diabetes mellitus (T2DM). In 4 double-blind, placebo-controlled, phase 3 trials, saxagliptin 2.5 or $5 \mathrm{mg}$ significantly reduced glycated hemoglobin $(\mathrm{HbA} 1 \mathrm{c})$ from baseline at 24 weeks. A pooled analysis of these clinical trials was conducted to assess the therapeutic profile of saxagliptin monotherapy.

Methods: A post hoc pooled analysis of 4 saxagliptin monotherapy trials in patients with T2DM was conducted to determine the consistency of treatment effects, assessed as change from baseline in $\mathrm{HbA} 1 \mathrm{c}$ at week 24, in patient subgroups stratified by race, sex, age, and baseline $\mathrm{HbA} 1 \mathrm{c}$. Secondary end points included change from baseline at week 24 in fasting plasma glucose and proportion of patients achieving $\mathrm{HbA} 1 \mathrm{c}<7 \%$. Safety assessments included adverse event reports, laboratory test results, and vital sign measurements.

Results: At week 24, saxagliptin $2.5 \mathrm{mg}$, saxagliptin $5 \mathrm{mg}$, and placebo decreased $\mathrm{HbA} 1 \mathrm{c}$ from baseline by $-0.66 \%,-0.64 \%$, and $-0.13 \%$ respectively ( $P<0.0001$ for each saxagliptin dose vs placebo). The treatment effects of saxagliptin $2.55 \mathrm{mg}$ on $\mathrm{HbA} 1 \mathrm{c}$ were consistent across subgroups, and no treatment interactions were observed, with the exception of baseline $\mathrm{HbA} 1 \mathrm{c}(P=0.003)$. The overall occurrence of adverse events was similar among groups ( $66.0 \%$ saxagliptin $2.5 \mathrm{mg} ; 53.0 \%$ saxagliptin $5 \mathrm{mg} ; 45.3 \%$ placebo). The incidence of hypoglycemic events was low and comparable among groups, and no cases of confirmed hypoglycemia were reported.

Conclusions: Consistent with findings from individual studies, this pooled analysis showed saxagliptin to significantly improve glycemic measures compared with placebo. Outcomes confirmed saxagliptin treatment was associated with a weight-neutral effect and a low risk for hypoglycemia. Based on the overall findings, saxagliptin has a favorable benefit:risk profile and may be considered an alternative first-line therapy for patients with T2DM in whom metformin is contraindicated or not tolerated.
\end{abstract}

Keywords: Type 2 diabetes mellitus; Saxagliptin; DPP-4 inhibitor; Glycated hemoglobin; Hypoglycemia; Metformin; Glycemic control

\section{Introduction}

Diabetes mellitus is a highly prevalent, chronic condition affecting more than 29 million people in the United States [1]. Diabetes affects numerous organ systems, and is associated with serious complications, including heart disease, stroke, kidney failure and lower-limb amputations [1].

In adults, type 2 diabetes mellitus (T2DM), which is characterized by insulin resistance with a progressive insulin secretion defect and $\beta$-cell failure, accounts for more than $90 \%$ of all diagnosed cases [13]. The natural history of T2DM has been well described, and it is now understood that multiple pathophysiologic defects contribute to hyperglycemia [3].

There is a well-established correlation between hyperglycemia, as measured by elevated glycated hemoglobin (HbAlc) levels, and an increased risk for microvascular and macrovascular complications $[4,5]$. Therefore, attaining good glycemic control may help prevent or delay long-term complications of T2DM, especially microvascular disease $[1,6]$. In an observational study, a reduction in the risk of T2DM complications was observed for every $1 \%$ decrease in HbAlc. The lowest risk for disease-related complications was observed in patients with $\mathrm{HbA1c}$ levels below 6.0\% [4].

Recent guidelines from the American Diabetes Association and European Association for the Study of Diabetes therefore recommend a therapeutic target of $<7 \% \mathrm{HbA} 1 \mathrm{c}$ for most adults with T2DM and a more stringent target of $<6.5 \%$ if this can be achieved without significant hypoglycemia or other treatment-related adverse effects [5]. However, less stringent HbAlc goals may be more appropriate for patients with a limited life expectancy, history of severe hypoglycemia, and extensive comorbid conditions [5]. It should be emphasized that glycemic targets should be individualized and tailored to the patient's preferences and needs [5].

There is a wide array of medications available to treat T2DM [7]. Aside from insulin, most medications are expected to reduce $\mathrm{HbAlc}$ levels by $0.5 \%$ to $2.0 \%$ when administered as monotherapy [8]. A reduction in $\mathrm{HbA} 1 \mathrm{c}$ of $0.5 \%$ is generally considered to be a clinically meaningful and therapeutic response $[9,10]$. Metformin, a biguanide, is the preferred initial pharmacologic therapy for T2DM because it has a long-standing evidence base of clinical efficacy and no associated risk for weight gain or hypoglycemia [2,11]. However, metformin is not

*Corresponding author: Boaz Hirshberg, CVMD Clinical Therapeutic Area, One Medlmmune Way, Building 200, Gaithersburg, MD 20878, USA, Tel: 301-3980645; E-mail: boaz.hirshberg@astrazeneca.com

Received January 19, 2015; Accepted March 16, 2015; Published March 20 2015

Citation: Hirshberg B, Bryzinski B, Xu J, Iqbal N (2015) A Pooled Analysis of the Efficacy and Safety of Saxagliptin as Monotherapy in Patients with Type 2 Diabetes. J Diabetes Metab 6: 524. doi:10.4172/2155-6156.1000524

Copyright: @ 2015 Hirshberg B, et al. This is an open-access article distributed under the terms of the Creative Commons Attribution License, which permits unrestricted use, distribution, and reproduction in any medium, provided the original author and source are credited. 
appropriate for all patients. It is contraindicated in patients with renal insufficiency and is commonly associated with gastrointestinal (GI) side effects, particularly in the early stages of treatment [12].

Dipeptidyl peptidase-4 (DPP-4) inhibitors are a newer class of antihyperglycemic therapy that targets the incretin system. The incretin hormones, glucagon-like peptide 1 (GLP-1) and glucose-dependent insulinotropic peptide (GIP), which are released from the intestinal tract, facilitate postprandial insulin secretion from the pancreas and account for approximately $50 \%$ of the postprandial insulin response [13]. GLP-1 has been shown to have multiple physiologic benefits, including stimulating glucose-dependent insulin secretion, decreasing glucagon secretion, and slowing gastric emptying [13,14]. Native GLP-1 and GIP, however, are degraded within minutes by the DPP4 enzyme [15]. Research has shown DPP-4 expression and activity to be higher in patients with T2DM compared with healthy controls [16]. By slowing the degradation of GLP-1 and GIP, DPP-4 inhibitors thus sustain the incretin effects of increasing postprandial insulin secretion and suppressing glucagon production [13]. Preclinical data have also suggested that DPP-4 inhibitors may limit $\beta$-cell apoptosis and stimulate $\beta$-cell proliferation [17]. Current guidelines support the addition of DPP-4 inhibitors for patients experiencing suboptimal glycemic control with metformin alone [2] or as a first-line alternative if metformin monotherapy cannot be tolerated [5,11].

Saxagliptin is a once-daily (QD), orally administered, potent, competitive, and reversible DPP-4 inhibitor [18,19]. Saxagliptin is currently approved as an adjunct to diet and exercise to improve glycemic control in adults with T2DM [20,21]. As appropriate, saxagliptin may also be used in combination with metformin, sulfonylureas (SUs), thiazolidinediones, insulin, and metformin plus an SU $[5,11]$.

In 4 individual phase 3 trials, saxagliptin monotherapy $(2.5$ or $5 \mathrm{mg}$ QD) significantly reduced $\mathrm{HbAlc}$ from baseline at 24 weeks compared with placebo [10,22-24]. Consistent with the characteristics of a DPP-4 inhibitor [5,11], saxagliptin was associated with a low risk of hypoglycemia and with weight neutrality [10,22-24]. A pooled analysis of these 4 phase 3 saxagliptin monotherapy trials was performed to better characterize the therapeutic profile of saxagliptin monotherapy for the treatment of T2DM.

\section{Methods}

This was a post hoc pooled analysis of all of the phase 3 , controlled, saxagliptin monotherapy trials in patients with T2DM (clinical trial registration: NCT00918879, NCT00316082, NCT00698932, NCT00121641). Each of the 4 studies had a similar study design and a primary end point of change from baseline in HbAlc at week 24 . Individual study methodology has been previously published [10,2224]. Briefly, the studies included patients with T2DM who were $\geq 18$ years of age and treatment-naïve, who had early-stage disease (HbAlc, $7 \%-10 \%)$, and who might otherwise seek first-line treatment with metformin [10,22-24]. All patients who met certain criteria for poor glycemic control were allowed rescue medication with metformin. In each study, patients with significant cardiovascular (CV) disease, or significant or unsTable renal disease were excluded. Of note, 2 of the 4 studies included only the saxagliptin 5-mg dose and were conducted in Asian populations [10,23].

All studies were performed in accordance with guidelines set forth by the International Conference on Harmonization and Declaration of Helsinki. Study protocol and amendments were approved by the individual review board/independent ethics committee for each participating site. All patients provided informed written consent.

\section{Study end points and assessments}

Pooled assessments were performed for the saxagliptin $2.5 \mathrm{mg}$, saxagliptin $5 \mathrm{mg}$, and placebo groups. The focus of this analysis was the primary end point of change from baseline in HbAlc at week 24. Subgroup analyses were performed to assess the consistency of treatment effects. Patients were stratified by race (white, Asian, black, other), sex, age ( $<65$ or $\geq 65$ years), and baseline HbAlc $(<8 \%, 8 \%$ $<9 \%$, or $\geq 9 \%$ ). Secondary end points included in this analysis were change from baseline in fasting plasma glucose (FPG) at week 24, proportion of patients achieving a therapeutic glycemic response (defined as $\mathrm{HbAlc}<7 \%$ ), and change from baseline in postprandial glucose (PPG) area under the curve (AUC), and 2-hour PPG.

For all efficacy evaluations, data were pooled for the saxagliptin 2.5-mg groups, saxagliptin 5-mg morning (AM) groups, and placebo groups. Data for patients who were titrated from saxagliptin $2.5 \mathrm{mg}$ to $5 \mathrm{mg}$, received saxagliptin $10 \mathrm{mg}$, or received saxagliptin $5 \mathrm{mg}$ in the evening (PM) were not included. All pooled efficacy analyses were performed on data collected before patients received rescue medication.

Safety and tolerability assessments were based on adverse event (AE) reports, laboratory test results, vital sign measurements, electrocardiogram, and physical examinations. Treatment-emergent AEs were defined as any new, untoward medical occurrence or worsening of a preexisting medical condition, regardless of relationship to the study treatment. A serious AE (SAE) was defined as any untoward medical condition that was fatal, life threatening, resulted or prolonged inpatient hospitalization, caused significant disability, resulted in a congenital anomaly or birth defect, or was considered an important medical event.

Safety events of special interest included those that were of potential importance to antihyperglycemic agents, were relevant to the mechanism of action of DPP-4 inhibitors or the safety profile of other DPP-4 inhibitors, or were selected based on preclinical and clinical findings from the saxagliptin clinical development program. AEs of special interest included hypoglycemia, infections (including opportunistic), GI-related AEs, CV events, hypersensitivity reactions, lymphopenia, thrombocytopenia, pancreatitis, skin disorders, and bone fractures. A confirmed hypoglycemic event was characterized as having symptoms of hypoglycemia and fingerstick glucose $\leq 50 \mathrm{mg} / \mathrm{dL}$.

For the safety analysis, data for the saxagliptin 2.5- to 5-mg titration group were pooled with the $2.5-\mathrm{mg}$ groups, and data from the saxagliptin 5-mg PM group were pooled with 5-mg AM groups; both groups were compared with the pooled placebo group. Data from the saxagliptin 10-mg group were not included.

\section{Statistical analyses}

The primary and secondary efficacy end points, including treatment by subgroup interactions, were evaluated using an analysis of covariance model that used last observation carried forward to account for missing data. Supportive efficacy analyses using repeated measures were also conducted.

\section{Results}

A total of 1452 randomized patients (saxagliptin $2.5 \mathrm{mg}, \mathrm{n}=247$; saxagliptin $5 \mathrm{mg}, \mathrm{n}=645$; placebo, $\mathrm{n}=560$ ) were included in this analysis. Of these patients, $73 \%$ completed 24 weeks of treatment 
in the saxagliptin 2.5 -mg group as did $84 \%$ in the saxagliptin 5 -mg group and $81 \%$ in the placebo group. In each treatment group, early discontinuation before 24 weeks was primarily due to perceived lack of efficacy with study medication or withdrawal of consent.

With the exception of race, patient demographics and disease characteristics were generally well balanced across treatment groups (Table 1). The mean age was 52 years, and $52 \%$ of patients were men. The mean weight was $77.4 \mathrm{~kg}$. Patients generally had recent-onset T2DM (mean duration at baseline, 1.5 years) and early-stage disease (mean baseline HbA1c, 8.1\%; mean baseline FPG, $164 \mathrm{mg} / \mathrm{dL}$ ).

\section{Efficacy analyses}

At week 24, saxagliptin $2.5 \mathrm{mg}$, saxagliptin $5 \mathrm{mg}$, and placebo decreased $\mathrm{HbAlc}$ from baseline by $-0.66 \%,-0.64 \%$, and $-0.13 \%$, respectively $(\mathrm{P}<0.0001$ for each saxagliptin dose vs placebo; Figure 1$)$. The treatment effects of saxagliptin on $\mathrm{HbAlc}$ were consistent across patient subgroups, and no treatment interactions were observed in subgroups categorized by race, sex, or age. However, a significant interaction was observed for baseline $\mathrm{HbAlc}(\mathrm{P}=0.003$; Figure 2).

Changes from baseline in FPG at week 24 were statistically significant with each saxagliptin dose compared with placebo $(\mathrm{P}<0.0001$; Figure 3). Saxagliptin $5 \mathrm{mg}$ also significantly increased the proportion

\begin{tabular}{|c|c|c|c|}
\hline & $\begin{array}{c}\text { Saxagliptin } \\
2.5 \mathrm{mg} \\
(\mathrm{n}=247)\end{array}$ & $\begin{array}{c}\text { Saxagliptin } \\
5 \mathrm{mg} \\
(\mathrm{n}=643)\end{array}$ & $\begin{array}{l}\text { Placebo } \\
(n=559)\end{array}$ \\
\hline Age , y & $54.2(10.4)$ & $52.1(10.3)$ & $51.9(10.8)$ \\
\hline$<65 y, n(\%)$ & $208(84.2)$ & $576(89.6)$ & $490(87.7)$ \\
\hline \multicolumn{4}{|l|}{ Sex, n (\%) } \\
\hline Women & $127(51.4)$ & $301(46.8)$ & $259(46.3)$ \\
\hline \multicolumn{4}{|l|}{ Race, n (\%) } \\
\hline White & $193(78.1)$ & $190(29.5)$ & $132(23.6)$ \\
\hline Asian & $37(15.0)$ & $431(67.0)$ & $410(73.3)$ \\
\hline Black & $12(4.9)$ & $18(2.8)$ & $10(1.8)$ \\
\hline Other & $5(2.0)$ & $4(0.6)$ & $7(1.3)$ \\
\hline Weight, kg & $87.7(17.9)$ & $76.2(17.5)$ & $74.7(15.5)$ \\
\hline $\mathrm{BMI}, \mathrm{kg} / \mathrm{m}^{2}$ & $31.1(4.8)$ & $28.1(4.9)$ & $27.7(4.6)$ \\
\hline Duration of T2DM , y & $2.2(3.0)$ & $1.3(2.6)$ & $1.4(2.5)$ \\
\hline $\mathrm{HbA} 1 \mathrm{c} \%$ & $8.0(1.0)$ & $8.1(0.9)$ & $8.1(0.9)$ \\
\hline \multicolumn{4}{|l|}{ HbA1c category, $n(\%)$} \\
\hline$<8.0 \%$ & $138(55.9)$ & $306(47.6)$ & $271(48.5)$ \\
\hline $8.0-<9.0 \%$ & $66(26.7)$ & $221(34.4)$ & $187(33.5)$ \\
\hline$\geq 9.0 \%$ & $43(17.4)$ & $116(18.0)$ & $101(18.1)$ \\
\hline FPG, mg/dL & $169.9(43.2)$ & $162.8(39.4)$ & $162.0(43.9)$ \\
\hline PPG 2-h AUC (SD), mg.min/dL & $\begin{array}{c}47470.0 \\
(11687.7)\end{array}$ & $\begin{array}{c}46743.1 \\
(10835.3)\end{array}$ & $\begin{array}{c}47209.6 \\
(11917.3)\end{array}$ \\
\hline Fasting insulin (SD), pmol/L & $15.4(10.2)$ & $13.2(13.7)$ & $11.8(9.4)$ \\
\hline $\begin{array}{c}\text { Creatinine } \\
\text { clearance, } \mathrm{mL} / \mathrm{min}\end{array}$ & $116.0(37.9)$ & $107.1(35.1)$ & 106.1 (36.1) \\
\hline
\end{tabular}

$A \cup C=$ area under the curve; $B M I=$ body mass index; $F P G=$ fasting plasma glucose $\mathrm{HbA1c}=$ glycated hemoglobin; PPG=postprandial glucose; T2DM=type 2 diabetes mellitus. Values are mean (SD) unless otherwise indicated.

*Safety population includes saxagliptin 2.5- to 5-mg titration group data pooled with 2.5-mg groups, data for 5-mg PM group pooled with 5-mg AM groups, and data pooled for placebo groups. Efficacy population includes pooled data for saxagliptin 2.5-mg groups (not including 2.5- to 5-mg titration group), saxagliptin 5-mg AM groups, and placebo groups.

Table 1: Patient Baseline Demographics and Disease Characteristics, Pooled Safety Population*.

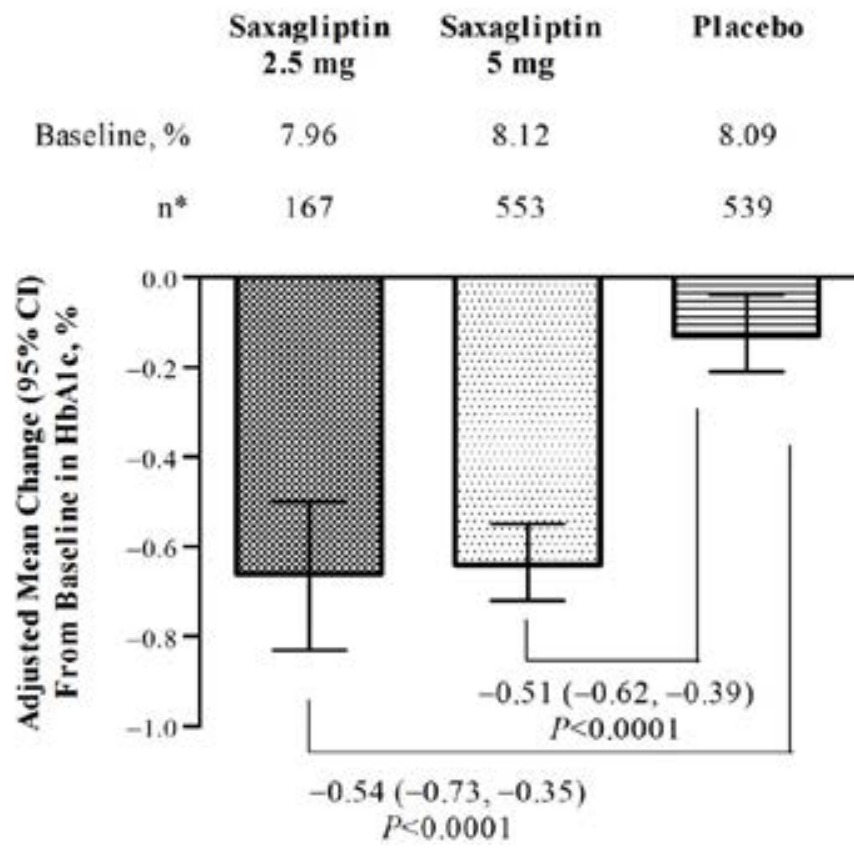

Figure 1: Adjusted mean $(95 \% \mathrm{Cl})$ change from baseline in $\mathrm{HbA} 1 \mathrm{c}$ at week 24. Number of patients by treatment group and $\mathrm{HbA1c}$ outcomes. Data collected before rescue treatment. Change from baseline in $\mathrm{HbA1c}$ was evaluated using an ANCOVA model with last observation carried forward to account for missing data. At week 24 , saxagliptin $2.5 \mathrm{mg}$ and saxagliptin $5 \mathrm{mg}$ significantly decreased $\mathrm{HbA} 1 \mathrm{c}$ from baseline compared with placebo $(P<0.0001$ for each saxagliptin dose). ANCOVA=analysis of covariance; $\mathrm{HbA} 1 \mathrm{c}=$ glycated hemoglobin. "Number of randomized patients with baseline and week 24 values.

of patients who achieved a therapeutic glycemic response (HbAlc $<7 \%)$ at week 24 compared with placebo $(\mathrm{P}<0.0001)$, although only a numerical increase was observed with saxagliptin $2.5 \mathrm{mg}$ (Figure 4). Changes from baseline in PPG AUC and 2-hour PPG at week 24 were statistically significant with each saxagliptin dose group versus placebo $(\mathrm{P}<0.001$; Figure 5). Supportive analyses using repeated measures were consistent with the primary analysis of change from baseline in $\mathrm{HbAlc}$ and FPG at week 24 and further demonstrated consistent treatment effects on $\mathrm{HbAlc}$ across patient subgroups (Supplementary Appendix).

At week 24, minor decreases in weight (mean [95\% CI]) from baseline were observed in the saxagliptin $2.5-\mathrm{mg}$ group $(-0.9[-1.3$, $-0.5] \mathrm{kg})$, saxagliptin $5-\mathrm{mg}$ group $(-0.4[-0.6,-0.2] \mathrm{kg})$, and placebo group $(-1.3[-1.5,-1.0] \mathrm{kg})$.

\section{Safety and tolerability}

Based on the pooled safety data, mean exposure was 20.6 weeks in the saxagliptin 2.5-mg group, 21.8 weeks in the saxagliptin 5-mg group, and 20.9 weeks in the placebo group. The majority of patients (74\%) were exposed to study medication for $\geq 23.7$ weeks, consistent with the number of patients who completed the 24-week study period.

The overall proportion of patients reporting AEs was similar across treatment groups, and no dose-response was observed (saxagliptin $2.5 \mathrm{mg}$, 66.0\%; saxagliptin $5 \mathrm{mg}, 53.0 \%$; placebo, $45.3 \%$; Table 2). The most common AEs ( $\geq 3 \%$ of patients) occurring in the saxagliptin dose groups were upper respiratory tract infection, urinary tract infection, and nasopharyngitis (Table 2). With the exception of hypoglycemia (discussed below), arthralgia was the only AE with an incidence of $\geq$ 
Citation: Hirshberg B, Bryzinski B, Xu J, Iqbal N (2015) A Pooled Analysis of the Efficacy and Safety of Saxagliptin as Monotherapy in Patients with Type 2 Diabetes. J Diabetes Metab 6: 524. doi:10.4172/2155-6156.1000524

Page 4 of 7

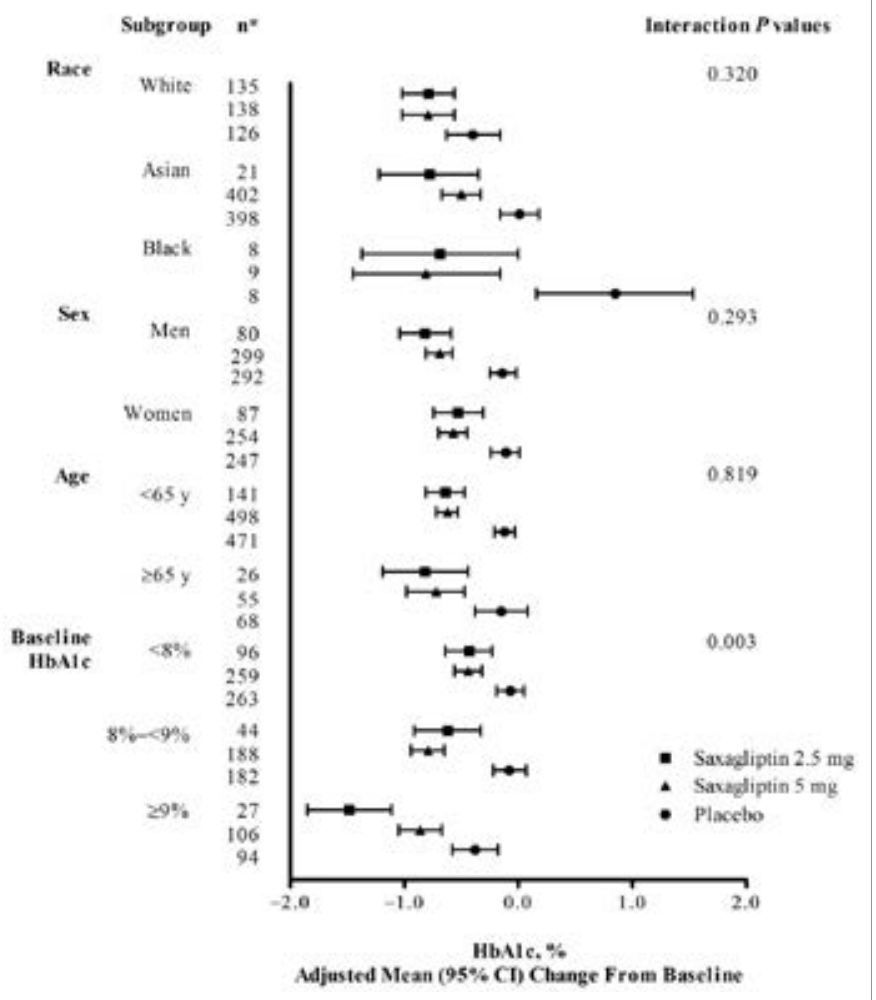

Figure 2: Adjusted mean $(95 \% \mathrm{Cl})$ change from baseline in $\mathrm{HbA} 1 \mathrm{C}$ at w24: subgroup analysis. Subgroup analyses were performed to assess the consistency of treatment effects on change from baseline in $\mathrm{HbA1c}$. Patients were stratified by race (white, Asian, black, other) sex, age $(<65$ or $\geq 65$ years), and baseline $\mathrm{HbA} 1 \mathrm{c}(<8 \%, 8 \%-<9 \%$, or $\geq 9 \%)$. Only a few patients identified as "other" in the subgroup for race (saxagliptin $2.5 \mathrm{mg}$, $\mathrm{n}=3$; saxagliptin $5 \mathrm{mg}, \mathrm{n}=4$; placebo, $\mathrm{n}=7$ ). The adjusted mean change $(95 \%$ $\mathrm{Cl}$ ) from baseline in $\mathrm{HbA} 1 \mathrm{c}$ in these patients was $-1.96(-3.06,-0.86)$ in the saxagliptin $2.5 \mathrm{mg}$ group, $-1.78(-2.74,-0.82)$ in the saxagliptin $5 \mathrm{mg}$ group, and $-0.06(-0.80,0.68)$ in the placebo group at week 24 . No significant treatment interaction was observed, with the exception of baseline $\mathrm{HbA} 1 \mathrm{c}$ $(P=0.003) . \mathrm{HbA} 1 \mathrm{c}=$ glycated hemoglobin. "Number of randomized patients with baseline and week 24 values.

$2 \%$ in the saxagliptin $5-\mathrm{mg}$ group with a difference of $>1 \%$ compared with placebo ( $2.6 \%$ vs $1.3 \%$, respectively).

The occurrence of SAEs and AEs leading to discontinuation was low $(<5 \%$ and $<3 \%$, respectively, in any treatment group; Table 2$)$. SAEs related to cardiac disorders were reported for $0.8 \%$ of patients in each saxagliptin group and for $0.2 \%$ of patients in the placebo group. In each case, the patient had either preexisting $\mathrm{CV}$ disease or multiple $\mathrm{CV}$ risk factors, and each event was considered not related or unlikely related to study treatment. Overall, no specific type of SAE or AE leading to discontinuation prevailed (Supplementary Appendix).

There were two deaths reported during the 24-week treatment period, 1 due to pneumococcal sepsis in the saxagliptin 2.5-mg group and 1 due to myocardial infarction (MI) in the saxagliptin 5-mg group. Neither death was considered related to study treatment. Two additional deaths were reported after the 24 -week treatment period, 1 due to cerebral hemorrhage in the placebo group and 1 due to pancreatic and hepatic cancer in the saxagliptin 2.5-mg group (approximately 16 months after treatment discontinuation). The incidence of reported hypoglycemic events was low and similar between the saxagliptin 2.5and 5 -mg groups (4.0\% and 3.0\%, respectively, vs $1.6 \%$ with placebo; Table 2). However, no hypoglycemic event was considered serious,

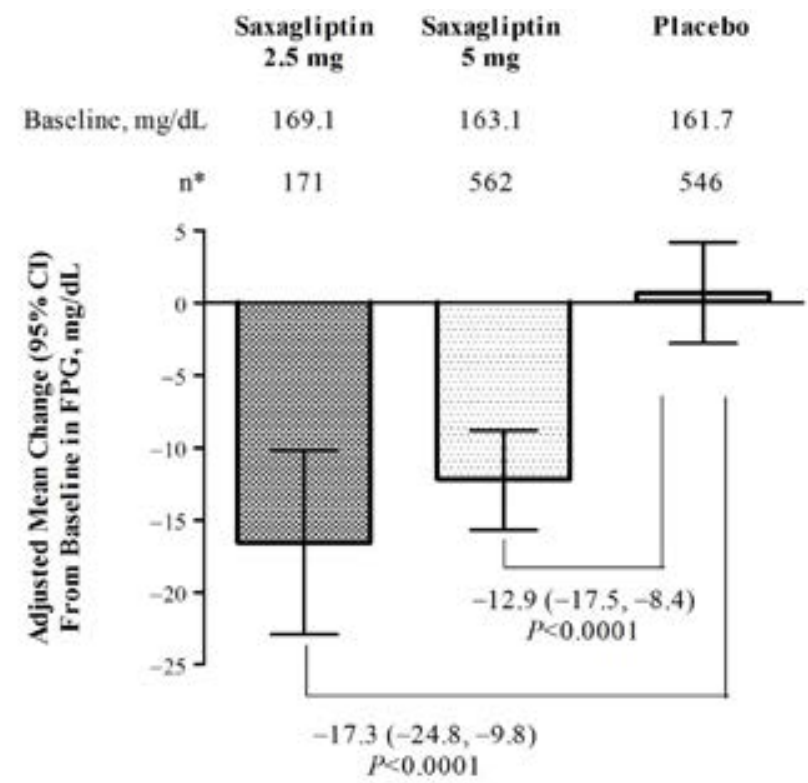

Figure 3: Adjusted mean $(95 \% \mathrm{Cl})$ change from baseline in FPG $(\mathrm{mg} / \mathrm{dL})$ at week 24. Number of patients by treatment group and FPG outcomes Data collected before receiving rescue medication. Change from baseline in FPG was evaluated using ANCOVA model with last observation carried forward to account for missing data. At week 24 , saxagliptin $2.5 \mathrm{mg}$ and $5 \mathrm{mg}$ significantly reduced FPG from baseline compared with placebo $(P<0.0001$ for each saxagliptin dose). ANCOVA=analysis of covariance; $F P G=$ fasting plasma glucose. Number of randomized patients with baseline and week 24 values.

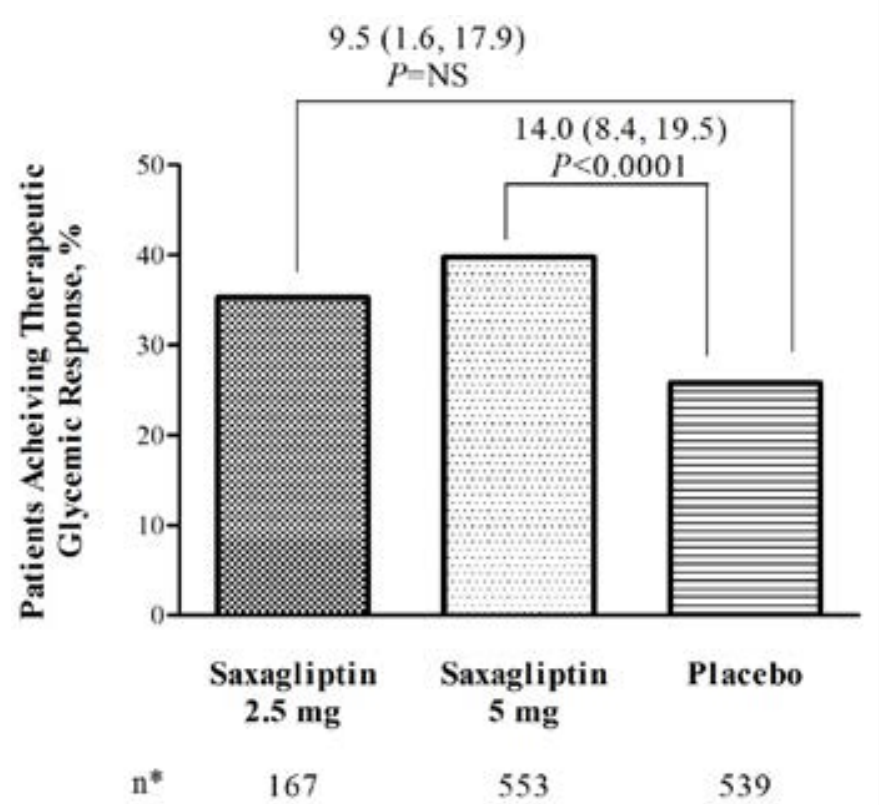

Figure 4: Proportion of patients achieving a therapeutic glycemic response $(\mathrm{HbA} 1 \mathrm{c}<7 \%)$ at week 24 . Proportion of patients achieving a therapeutic glycemic response. Data collected before receiving rescue medication. The proportion of patients achieving $\mathrm{HbA} 1 \mathrm{c}$ was evaluated using ANCOVA model with last observation carried forward to account for missing data. Compared with placebo, saxagliptin $5 \mathrm{mg}$ significantly increased the proportion of patients who achieved $\mathrm{HbA} 1 \mathrm{c}<7 \%$ at week $24(P<0.0001)$ and saxagliptin $2.5 \mathrm{mg}$ was associated with a numerical increase. ANCOVA=analysis of covariance; $\mathrm{HbA} 1 \mathrm{c}=$ glycated hemoglobin; NS=not significant. *Number of randomized patients with week 24 values. 
Citation: Hirshberg B, Bryzinski B, Xu J, Iqbal N (2015) A Pooled Analysis of the Efficacy and Safety of Saxagliptin as Monotherapy in Patients with Type 2 Diabetes. J Diabetes Metab 6: 524. doi:10.4172/2155-6156.1000524

Page 5 of 7

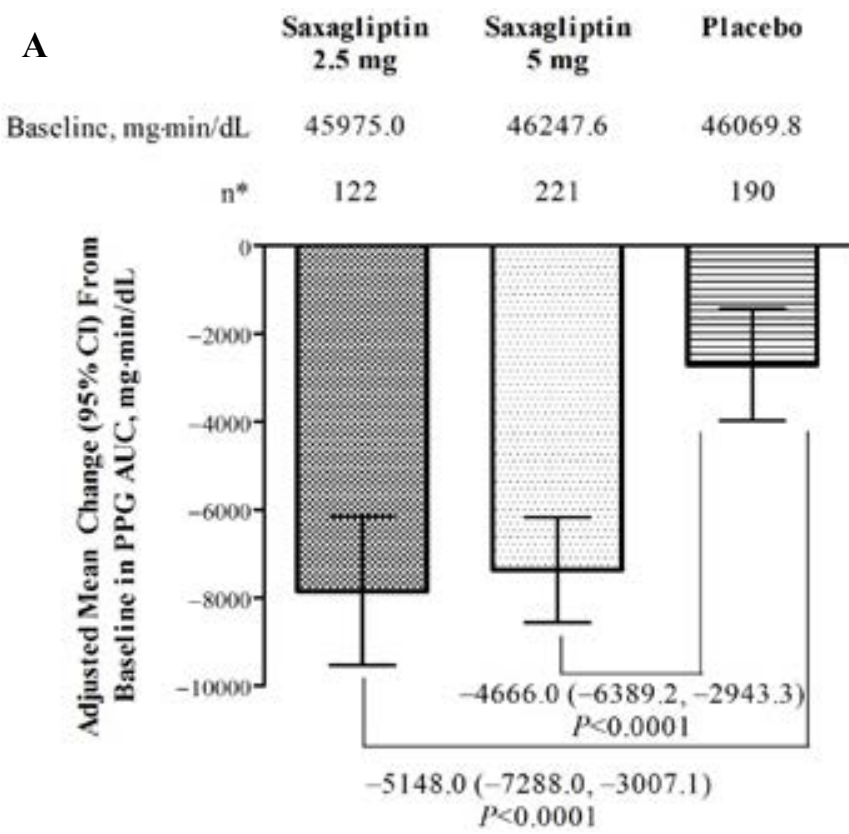

B

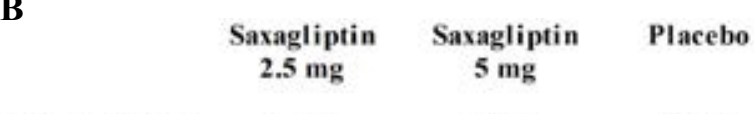

Baseline, $\mathrm{mg} / \mathrm{dL} \quad 283.1 \quad 284,3$

$225 \quad 195$

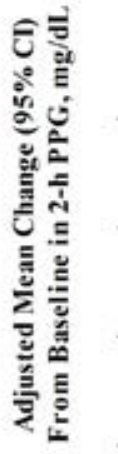

$n^{*}-126$
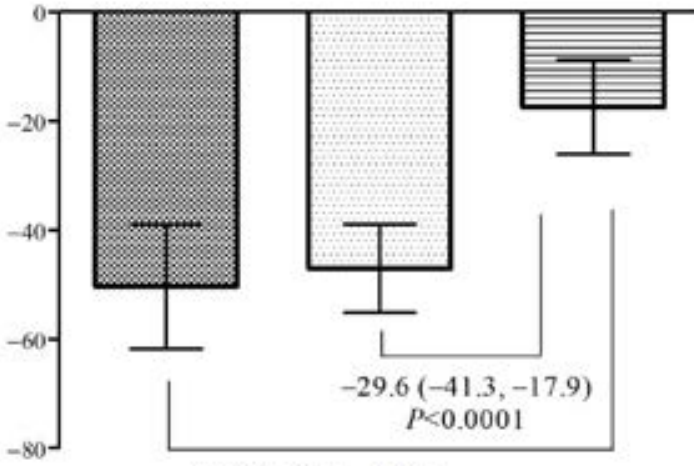

$-33.0(-47.4,-18.5)$

$P<0,0001$

Figure 5: Adjusted mean $(95 \% \mathrm{Cl})$ change from baseline in (A) PPG AUC $(\mathrm{mg} \cdot \mathrm{min} / \mathrm{dL})$ and $(B)$ 2-hour PPG $(\mathrm{mg} / \mathrm{dL})$ at week 24. Number of patients by treatment group and PPG AUC and 2-hour PPG outcomes. Data collected before receiving rescue medication. PPG-AUC and 2-hour PPG were evaluated by ANCOVA model with last observation carried forward to account for missing data. At week 24, changes from baseline in PPG AUC and 2-hour PPG were statistically significant with saxagliptin $2.5 \mathrm{mg}$ and saxagliptin $5 \mathrm{mg}$ vs placebo $(P<0.001$ for each dose). ANCOVA=analysis of covariance; $A \cup C=$ area under the curve; $P P G=$ postprandial glucose. "Number of randomized patients with baseline and week 24 values.

led to treatment discontinuation, or required medical management or third-party assistance. There were no cases of confirmed hypoglycemia.

There was no increased risk for infection with saxagliptin $5 \mathrm{mg}$ compared with placebo ( $22.1 \%$ vs $18.1 \%$, respectively), although a higher occurrence of infection was observed with saxagliptin $2.5 \mathrm{mg}$
(30.4\%). There was no also notable association between saxagliptin and GI tolerability issues (Table 2 and Supplementary Appendix). Diarrhea was the most commonly reported GI-related AE; however, the overall incidence was low ( $<5 \%$ in each saxagliptin group). Two serious GI-related AEs, abdominal pain and intestinal obstruction, were reported in 1 patient each in the saxagliptin 5 -mg group. Two GIrelated AEs leading to treatment discontinuation were also reported in the saxagliptin 5-mg group: 1 patient each reporting dry mouth and gastric disorder.

Hypersensitivity reactions occurred infrequently $(<3 \%$ in any treatment group), and no events were considered serious or led to treatment discontinuation. The incidence of individual AEs related to cardiac disorders was low: less than $1 \%$ in any treatment group. CV SAEs reported in the saxagliptin 2.5-mg, saxagliptin 5-mg, and placebo groups included unstable angina $(0.4 \%, 0.3 \%$, and 0 , respectively), atrial fibrillation $(0.4 \%, 0.2 \%$, and 0$)$, MI $(0,0.2 \%$, and 0$)$, cerebrovascular accident $(0,0.3 \%$, and 0$)$, supraventricular tachycardia $(0,0.2 \%$, and 0$)$, and coronary artery disease $(0,0$, and $0.2 \%)$.

All other AEs of special interest, including opportunistic infections, lymphopenia, thrombocytopenia, pancreatitis, skin disorders, and bone fracture, occurred in $<1 \%$ of patients in any treatment group. Subgroup analyses by sex, age, and race showed no difference in the type or incidence of AEs across patients. Overall, there was no notable difference in the incidence of marked laboratory abnormalities among treatment groups.

\section{Discussion}

Findings from this pooled analysis of 4 phase 3 clinical trials provide greater insight on the efficacy, safety, and tolerability of saxagliptin in

\begin{tabular}{|l|c|c|c|}
\hline & $\begin{array}{c}\text { Saxagliptin 2.5 } \\
\text { (n=247) }\end{array}$ & $\begin{array}{c}\text { Saxagliptin 5 mg } \\
\text { (n=643) }\end{array}$ & $\begin{array}{c}\text { Placebo } \\
\text { (n=559) }\end{array}$ \\
\hline Any AE, n (\%) & $163(66.0)$ & $341(53.0)$ & $253(45.3)$ \\
\hline Any related AE* & $35(14.2)$ & $62(9.6)$ & $38(6.8)$ \\
\hline Any SAE & $12(4.9)$ & $18(2.8)$ & $9(1.6)$ \\
\hline Deaths & $1(0.4)$ & $1(0.2)$ & 0 \\
\hline $\begin{array}{l}\text { Any AE leading to } \\
\text { discontinuation }\end{array}$ & $7(2.8)$ & $7(1.1)$ & $3(0.5)$ \\
\hline $\begin{array}{l}\text { Any SAE leading to } \\
\text { discontinuation }\end{array}$ & $3(1.2)$ & 0 & $2(0.4)$ \\
\hline Most common AEs $(\geq 3 \%$ in any group), n (\%) & & \\
\hline $\begin{array}{l}\text { Upper respiratory tract } \\
\text { infection }\end{array}$ & $21(8.5)$ & $39(6.1)$ & $41(7.3)$ \\
\hline Urinary tract infection & $12(4.9)$ & $27(4.2)$ & $26(4.7)$ \\
\hline Nasopharyngitis & $12(4.9)$ & $25(3.9)$ & $17(3.0)$ \\
\hline Headache & $9(3.6)$ & $22(3.4)$ & $19(3.4)$ \\
\hline Diarrhea & $11(4.5)$ & $16(2.5)$ & $9(1.6)$ \\
\hline Dizziness & $3(1.2)$ & $15(2.3)$ & $17(3.0)$ \\
\hline Pain in extremity & $12(4.9)$ & $13(2.0)$ & $8(1.4)$ \\
\hline Cough & $9(3.6)$ & $12(1.9)$ & $14(2.5)$ \\
\hline Peripheral edema & $9(3.6)$ & $8(1.2)$ & $5(0.9)$ \\
\hline Sinusitis & $11(4.5)$ & $8(1.2)$ & $3(0.5)$ \\
\hline Dyspepsia & $8(3.2)$ & $2(0.3)$ & $1(0.2)$ \\
\hline Hypoglycemic events ${ }^{\ddagger}$ & $10(4.0)$ & $19(3.0)$ & $9(1.6)$ \\
\hline AF andverse & & & \\
\hline
\end{tabular}

$\mathrm{AE}=$ adverse event; $\mathrm{SAE}=$ serious adverse event.

"Events considered by investigators to be related to study treatment.

${ }^{+}$Presented in descending order by preferred term in the saxagliptin 5-mg group ‡No events of confirmed hypoglycemia (symptoms of hypoglycemia and finger stick glucose reading of $\leq 50 \mathrm{mg} / \mathrm{dL}$ ) reported. 
patients with T2DM. Consistent with the individual studies [10,22-24], saxagliptin 2.5 and $5 \mathrm{mg}$ significantly reduced $\mathrm{HbA} 1 \mathrm{c}$ from baseline at week 24 compared with placebo.

Saxagliptin produced a clinically meaningful and therapeutic response $[9,10]$, as evidenced by changes from baseline in $\mathrm{HbAlc}$ that exceeded those achieved with placebo by $\geq 0.5 \%$. Secondary efficacy outcomes supplement these findings and further demonstrate the clinical benefit of saxagliptin on glycemic measures.

Given the baseline demographics and characteristics included in the individual studies, pooling allowed a comprehensive evaluation of saxagliptin in a diverse study population. The treatment effect of saxagliptin was consistent across patient subgroups categorized by race, sex, and age. The only notable treatment interaction was observed in patients with higher HbAlc at baseline $(\geq 9 \%)$. However, a greater treatment effect in patients with higher baseline HbAlc levels is consistent with previous observations with oral antidiabetic drugs [25].

Pooled safety data were consistent with the known profile of saxagliptin and DPP-4 inhibitors [5,11], and no new or unexpected safety issues emerged. Although metformin is widely accepted as the preferred first-line pharmacologic treatment in T2DM [5,11], lack of tolerability and contraindications may bar its use in some patients. For example, nearly $90 \%$ of patients starting metformin therapy report GI symptoms (eg, diarrhea, heartburn, nausea), the presence of which is associated with decreased quality of life and adherence [26]. This may be especially problematic for patients with diabetes who have preexisting GI complications caused by abnormal intestinal motility secondary to diabetic autonomic neuropathy [27]. Metformin is contraindicated in patients with renal dysfunction or disease (serum creatinine levels $\geq 1.4$ in women and $\geq 1.5$ in men) [12]. Because increased age is associated with reduced renal function, this could limit the use of metformin in some elderly patients [12]. In contrast, saxagliptin is not associated with GI tolerability issues [10,22-24], and the incidence of AEs and hypoglycemic events with saxagliptin $2.5 \mathrm{mg}$ (the recommended dose for patients with moderate or severe renal impairment or endstage renal disease) was similar to that of placebo in patients with renal impairment [28]. Therefore, saxagliptin could be considered an alternative treatment in patients for whom metformin is not tolerated or contraindicated.

Additional findings from the saxagliptin clinical development program supplement those reported here and provide greater insight on treatment effects in a patient population commonly burdened with serious comorbidities. For example, the Saxagliptin Assessment of Vascular Outcomes Recorded in patients with diabetes mellitus (SAVOR) trial included 16,492 patients with T2DM and established $\mathrm{CV}$ disease or multiple CV risk factors, many of whom also had mild-to-moderate renal impairment [29]. Findings showed there was no difference in the occurrence of the primary composite end point of $\mathrm{CV}$ death, myocardial infarction, or stroke between saxagliptin (7.3\%) and placebo groups (7.2\%; $P=0.99$ for superiority, $P<0.001$ for noninferiority) in patients with $\mathrm{CV}$ disease or risk factors. The occurrence of the secondary end point (primary composite end point plus hospitalization for heart failure, coronary revascularization, or unstable angina) also did not differ significantly between saxagliptin and placebo groups $(12.8 \%$ and $12.4 \%$, respectively; $P=0.66$ for superiority, $P<0.001$ for noninferiority). Analysis of the individual components of the secondary end point showed a higher incidence of hospitalization for heart failure in patients treated with saxagliptin compared with placebo ( $3.5 \%$ vs $2.8 \% ; P=0.007)$. However, this finding was unexpected, and the statistical analysis of this secondary component was not adjusted for multiplicity, which could have resulted in a false-positive result, and thus warrants further study [29]. It may be noted that deaths due to heart failure were similar for saxagliptin and placebo ( $0.5 \%$ each). Supplementary findings also showed HbAlc was significantly lower with saxagliptin versus placebo at 1 year, 2 years, and end of treatment $(P<0.001$ for all) [30]. Additional ongoing trials of DPP-4 inhibitors in large populations of patients with T2DM and diverse medical histories will help further establish the CV risk profile of these treatments [31-33].

Although this analysis was somewhat limited by the inherent differences among the 4 studies (eg, differences in doses studied, patient ethnicities), these differences do not preclude the value of pooling these data. Numerical comparison of the relative efficacy from the pooled analyses for the $2.5-\mathrm{mg}$ saxagliptin dose should be interpreted with caution because this dose was only examined in 2 of the 4 studies. However, no treatment-by-study interaction was observed for any of the doses in the pooled analysis, and saxagliptin $2.5 \mathrm{mg}$ produced clinically relevant and statistically significant reductions in $\mathrm{HbAlc}$ that were similar to those noted with the saxagliptin 5-mg dose.

\section{Conclusions}

This pooled analysis provides a comprehensive assessment of the therapeutic profile of saxagliptin monotherapy and further establishes its efficacy and tolerability in patients with T2DM. Based on these overall findings, in addition to the findings from the SAVOR trial, saxagliptin is associated with a generally favorable benefit:risk profile, and may be considered an alternative first-line therapy for patients with T2DM in whom metformin is contraindicated or not tolerated.

\section{Acknowledgment}

Editorial support was provided by Meg Church, MS, and Janet Matsuura, PhD, of Complete Healthcare Communications, Inc.(Chadds Ford, PA) and was funded by AstraZeneca.

\section{References}

1. Centers for Disease Control and Prevention (2014) National diabetes statistics report, 2014: estimates of diabetes and its burden in the United States. US Department of Health and Human Services, Centers for Disease Control and Prevention.

2. American Diabetes Association (2014) Standards of medical care in diabetes--2014. Diabetes Care 37: S14-80.

3. Defronzo RA (2009) Banting Lecture. From the triumvirate to the ominous octet a new paradigm for the treatment of type 2 diabetes mellitus. See comment in PubMed Commons below Diabetes 58: 773-795.

4. Stratton IM, Adler AI, Neil HA, Matthews DR, Manley SE, et al. (2000) Association of glycaemia with macrovascular and microvascular complications of type 2 diabetes (UKPDS 35): prospective observational study. See comment in PubMed Commons below BMJ 321: 405-412.

5. Inzucchi SE, Bergenstal RM, Buse JB, Diamant M, Ferrannini E, et al (2012) Management of hyperglycemia in type 2 diabetes: a patient-centered approach: position statement of the American Diabetes Association (ADA) and the European Association for the Study of Diabetes (EASD). Diabetes Care 35: $1364-1379$

6. UK Prospective Diabetes Study Group (1998) Intensive blood-glucose contro with sulphonylureas or insulin compared with conventional treatment and risk of complications in patients with type 2 diabetes (UKPDS 33). Lancet 352: 837 853

7. Nyenwe EA, Jerkins TW, Umpierrez GE, Kitabchi AE (2011) Management of type 2 diabetes: evolving strategies for the treatment of patients with type 2 diabetes. See comment in PubMed Commons below Metabolism 60: 1-23.

8. Nathan DM, Buse JB, Davidson MB, Ferrannini E, Holman RR, et al (2009) Medical management of hyperglycemia in type 2 diabetes: a consensus algorithm for the initiation and adjustment of therapy: a consensus statement of 
Citation: Hirshberg B, Bryzinski B, Xu J, Iqbal N (2015) A Pooled Analysis of the Efficacy and Safety of Saxagliptin as Monotherapy in Patients with Type 2 Diabetes. J Diabetes Metab 6: 524. doi:10.4172/2155-6156.1000524

the American Diabetes Association and the European Association for the Study of Diabetes. Diabetes Care 32: 193-203.

9. Hassaballa HA, Tulaimat A, Herdegen JJ, Mokhlesi B (2005) The effect of continuous positive airway pressure on glucose control in diabetic patients with severe obstructive sleep apnea. See comment in PubMed Commons below Sleep Breath 9: 176-180.

10. Kumar KMP, Jain SM, Tou C, Schützer K-M (2014) Saxagliptin as initial therapy in treatment-naive Indian adults with type 2 diabetes mellitus inadequately controlled with diet and exercise alone: a randomized, double-blind, placebocontrolled, phase IIlb clinical study. Int J Diabetes Dev Ctries 13: 33

11. Garber AJ, Abrahamson MJ, Barzilay JI, Blonde L, Bloomgarden ZT, et al (2013) AACE Comprehensive Diabetes Management Algorithm 2013. Endocr Pract 19: 327-336.

12. Glucophage (metformin hydrochloride) and Glucophage XR (metformin hydrochloride extended-release). Full Prescribing Information, Bristol-Myers Squibb Company, Princeton, NJ, 2009.

13. Neumiller JJ, Campbell RK (2010) Saxagliptin: a dipeptidyl peptidase-4 inhibitor for the treatment of type 2 diabetes mellitus. See comment in PubMed Commons below Am J Health Syst Pharm 67: 1515-1525

14. Holst JJ, Gromada J (2004) Role of incretin hormones in the regulation of insulin secretion in diabetic and nondiabetic humans. See comment in PubMed Commons below Am J Physiol Endocrinol Metab 287: E199-206.

15. Neumiller JJ, Wood L, Campbell RK (2010) Dipeptidyl peptidase-4 inhibitors for the treatment of type 2 diabetes mellitus. See comment in PubMed Commons below Pharmacotherapy 30: 463-484.

16. Lee SA, Kim YR, Yang EJ, Kwon EJ, Kim SH, et al. (2013) CD26/DPP4 levels in peripheral blood and $T$ cells in patients with type 2 diabetes mellitus. See comment in PubMed Commons below J Clin Endocrinol Metab 98: 2553-2561.

17. Duttaroy A, Voelker F, Merriam K, Zhang X, Ren X, et al. (2011) The DPP-4 inhibitor vildagliptin increases pancreatic beta cell mass in neonatal rats. See comment in PubMed Commons below Eur J Pharmacol 650: 703-707.

18. Dave DJ (2011) Saxagliptin: A dipeptidyl peptidase-4 inhibitor in the treatment of type 2 diabetes mellitus. J Pharmacol Pharmacother 2: 230-235.

19. Patel CG, Kornhauser D, Vachharajani N, Komoroski B, Brenner E, et al (2011) Saxagliptin, a potent, selective inhibitor of DPP-4, does not alter the pharmacokinetics of three oral antidiabetic drugs (metformin, glyburide or pioglitazone) in healthy subjects. Diabetes Obes Metab 13: 604-614.

20. Onglyza (2013) Summary of product characteristics.

21. Onglyza ${ }^{\circledR}$ (saxagliptin). Full Prescribing Information, Bristol-Myers Squibb Company, Princeton, NJ, 2013.

22. Frederich R, McNeill R, Berglind N, Fleming D, Chen R (2012) The efficacy and safety of the dipeptidyl peptidase- 4 inhibitor saxagliptin in treatment-naive patients with type 2 diabetes mellitus: a randomized controlled trial. Diabetol Metab Syndr 4: 36

23. Pan CY, Yang W, Tou C, Gause-Nilsson I, Zhao J (2012) Efficacy and safety of saxagliptin in drug-naïve Asian patients with type 2 diabetes mellitus: a randomized controlled trial. See comment in PubMed Commons below Diabetes Metab Res Rev 28: 268-275.

24. Rosenstock J, Aguilar-Salinas C, Klein E, Nepal S, List J, et al. (2009) Effect of saxagliptin monotherapy in treatment-naïve patients with type 2 diabetes. See comment in PubMed Commons below Curr Med Res Opin 25: 2401-2411.

25. Sherifali D, Nerenberg K, Pullenayegum E, Cheng JE, Gerstein HC (2010) The effect of oral antidiabetic agents on A1C levels: a systematic review and meta-analysis. See comment in PubMed Commons below Diabetes Care 33 : 1859-1864.

26. Florez H, Luo J, Castillo-Florez S, Mitsi G, Hanna J, et al. (2010) Impact of metformin-induced gastrointestinal symptoms on quality of life and adherence in patients with type 2 diabetes. See comment in PubMed Commons below Postgrad Med 122: 112-120.

27. Shakil A, Church RJ, Rao SS (2008) Gastrointestinal complications of diabetes Am Fam Physician 77: 1697-1702.

28. Nowicki M, Rychlik I, Haller H, Warren ML, Suchower L, et al. (2011) Saxagliptin improves glycaemic control and is well tolerated in patients with type 2 diabetes mellitus and renal impairment. See comment in PubMed Commons below Diabetes Obes Metab 13: 523-532.

29. Scirica BM, Bhatt DL, Braunwald E, Steg PG, Davidson J, et al. (2013) Saxagliptin and cardiovascular outcomes in patients with type 2 diabetes mellitus. See comment in PubMed Commons below N Engl J Med 369: 13171326.

30. Scirica BM, Bhatt DL, Braunwald E, Steg PG, Davidson J, et al. (2013) Supplement to: Saxagliptin and cardiovascular outcomes in patients with type 2 diabetes mellitus. N Engl J Med 369: 1317-1326.

31. Green JB, Bethel MA, Paul SK, Ring A, Kaufman KD, et al. (2013) Rationale, design, and organization of a randomized, controlled Trial Evaluating Cardiovascular Outcomes with Sitagliptin (TECOS) in patients with type 2 diabetes and established cardiovascular disease. Am Heart J 166: 983-989 e987.

32. Boehringer Ingelheim Pharmaceuticals. CAROLINA: Cardiovascular Outcome Study of Linagliptin Versus Glimepiride in Patients With Type 2 Diabetes [ClinicalTrials.gov identifier NCT01243424]. US National Institutes of Health ClinicalTrials.gov [online].

33. Boehringer Ingelheim Pharmaceuticals. CARMELINA: Cardiovascular and Renal Microvascular Outcome Study With Linagliptin in patients with type 2 diabetes mellitus at high vascular risk. US National Institutes of Health, ClinicalTrials.gov 